\title{
The Result of Functional Mobility Scale (FMS) on Cerebral Palsy Spastic Diplegic that treated by SEMLS (Single Event Multi Level Surgey) method in Orthopaedic Hospital Prof. Dr. R. Soeharso, Surakarta
}

\author{
Seti Aji Hadinoto, Anung Budi Satriadi, Hari Wujoso \\ Masters Program of Family Medicine, Sebelas Maret University
}

\begin{abstract}
Background: Cerebral Palsy is a permanent non-progressive brain disorders that occur in early childhood where abnormalities in the brain due to damage on immature brain can cause movement disorders and postural dysfunctionNowadays, the treatment of choice for CP Spastic diplegic is using SEMLS (Single Event Multi Level Surgery). There was many scoring to evaluate outcome of SEMLS, but only a few scoring system that can evaluate changing after SEMLS. Functional Mobility Scale (FMS) is an outcome measure designed to evaluate mobility of children with cerebral palsy (CP). FMS has been shown to detect both improvement and deterioration in mobility status during the rehabilitation period following multilevel orthopaedic surgery in children with spastic diplegic

Subjects and Method:This was a cross sectional observasional study. The sample are obtained by sensus from January $1^{\text {st }} 2014$ untill March $1^{\text {st }} 2015$. The patient's characteristic that we include in this study are gender, age when the patient had a surgery, and where the contracture are involved. We evaluate the outcome using FMS before operation, 3 month, 6 month, 9 month, and 12 month after operation on three different distance $(5,50,500$ meter) that represent home, school, and community. After that we analyze the result using regression logistic model to better understands about changes and time of changes on patient after SEMLS procedure. We also analyze the corelation between age, sex, and location of contracture with the outcome after SEMLS procedure
\end{abstract}

Result : 51 patients were reviewed and identified, there were 31 males (61\%) and 20 females (39\%), mean age when the patient was operated was 8.07 years old, with the most common cases are CP Spastic Diplegic with hip, knee, ankle contracture bilateral about 41 patient (80.3\%), knee ankle bilateral about 7 patient (13.2\%), and hip ankle bilateral about 3 patient (5.88\%). From evaluation of FMS scoring, we found most patient had an improvement on their mobility after SEMLS procedure (OR $>1$ ), with the time changes for 5 and 50 meters distance is at six months $(\mathrm{OR}: 1.52)$ and $(\mathrm{OR}=1.47)$, and 500 meters is at 12 months $(\mathrm{OR}=3.45)$. We also found no significant relationships $(\mathrm{p}$ value $>0.05)$ between age $(\mathrm{p}$ value $=0.632)$, sex $(\mathrm{p}$ value $=0.576)$ and location of contracture ( $\mathrm{p}$ value $=0.222$ ) with the outcome of the FMS after SEMLS

Conclusion: We found that SEMLS gives a good result to increased mobility of patient with CP Spastic Diplegic. FMS Score were able to asses the outcome of SEMLS procedure, and also responsive to change that occur after SEMLS. Age, sex, and contracture's location were not significantly influence the FMS outcome after SEMLS

Keywords: CP Spastic Diplegic, SEMLS (Single Event Muti Level Surgery), FMS (Functional Mobility Scale).

\section{Correspondence:}

Seti Aji Hadinoto. Masters Program of Family Medicine, Sebelas Maret University, Jl. Ir. Sutami 36 A, Surakarta 57126, Central Java. 


\section{BACKGROUND}

Cerebral Palsy is a permanent nonprogressive brain disorders that occur in early childhood where abnormalities in the brain due to damage on immature brain can cause movement disorders and postural dysfunctionO'shea M (2011).

From a recent study, the prevalence of Cerebral Palsy (CP) was estimated between 2.4 and 2.7 out of 1000 live birthsHerring $\mathrm{J}$ (2008). Increased incidence of CP supposedly correlates with increased survival rates of premature or low birth weight children Cerebral Palsy most commonly experienced by male infants. In a study conducted by Johnstoneand Hagberg (2007); Jarvis et al., (2005) CP cases is more commonly observed in male gender as much as 30\% when compared with female gender.

$\mathrm{CP}$ management is divided into non operative and operative actions. Non operative CP management includemedication, splinting, bracing, physical rehabilitation therapy or other adjuncttive therapy (e.g. neurodevelopmental therapy, serial cast correction, antispastic oral medication, and injections for focal spastic) (Sawyer, 2007).

Operative CP management is indicated when contracture or deformities have a big impact on limb function, causing pain or interfere with daily activities. This is the most effective management to treat fixed contracture(Sawyer, 2007).

Single-event multi-level surgery (SEMLS) is a corrective surgery that correct all orthopedic deformities at the same time, with soft tissue and bone surgery at two or more different anatomical locations for rehabilitation syndrome at a time so as to prevent birthday syndrome(Graham and Harvey, 2007; Harvey et al.,2007).The goal of SEMLSis to improve gaitThomason et al., 2011).According to study conducted by Rang et al., they reported that walking will reach its peak at the age of 7 years, so it is advisable to do SEMLS surgery when the child is 7 years old (O'shea, 2011; Khwaja and Volpe, 2008).

There are various scoring methods that have been developed to analyze the ability and limitation of functional activity of children with $\mathrm{CP}$, both before and after the surgery such as Gross Motor Functional Classification Score (GMFCS), Functional Mobility Scale (FMS), Functional Assessment Questionnaire (FAQ), Children Health Questionnaire (CHQ), and Pediatric Outcomes Data Collection Instrument (PODCI) (Harvey and Morris, 2008).

The aims of this study is to evaluate the success rate of SEMLS on spastic diplegic CP patients that conducted in Paediatric Clinic Prof. Dr. R. Soeharso, Surakarta Orthopedic Hospital and to determinewhether there is an influence between age, gender, and number of surgical procedures performed on patients with the success rate SEMLS. Success rate is measured using FMS.

\section{SUBJECTS AND METHOD}

This was an analytic observasional study with cross-sectional design. The study was conducted at the Paediatrics' Outpatient Departement of Prof. Dr. dr. R. Soeharso, Surakarta Orthopedic Hospital from January 1, 2014 to March 1, 2015.

The population were all patients with Spastic diplegic Cerebral Palsy in Paediatric Clinic Prof. Dr. R. Soeharso, Surakarta Orthopedic Hospital that have been performed SEMLS.

The samples used were patients with Spastic diplegic Cerebral Palsy in Paediatric Clinic Prof. Dr. R. Soeharso Surakarta Orthopedic Hospital that have been performed SEMLS that fulfill inclusion criteria 
Indonesian Journal of Medicine (2017), 2(2): 100-106 https://doi.org/10.26911/theijmed.2017.02.02.04

All the samplesare then evaluated using FMS questionnaire to their parents or the patients themselves. Outcome expressed by FMS score changes at different evaluation time i.e before operation, 3 month, 6 month, 9 month and 12 month after operation.

Regression logistics model is used to evaluate the correlation between SEMLS with therapy outcome(significance level: $p$ $<0.05$ ). Odds Ratio (OR) $<1$ means the child is experiencing deterioration. Odds Ratio (OR) > 1 means the child is experiencing improvement after operation. Correlation between ages, gender,and locations of surgery with SEMLS outcome is assessed by correlation method.

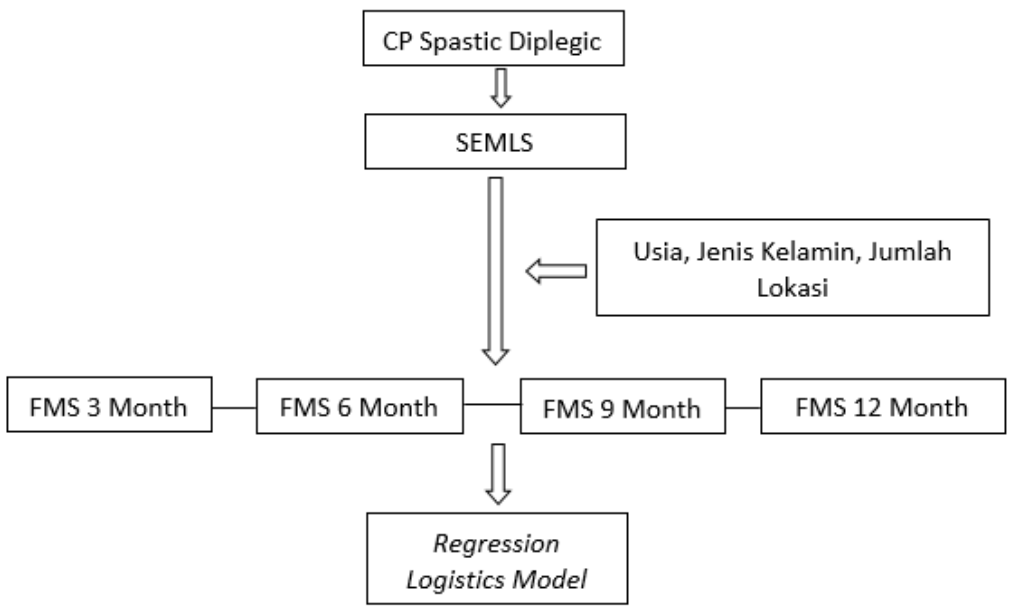

Picture 1. Conceptual Framework
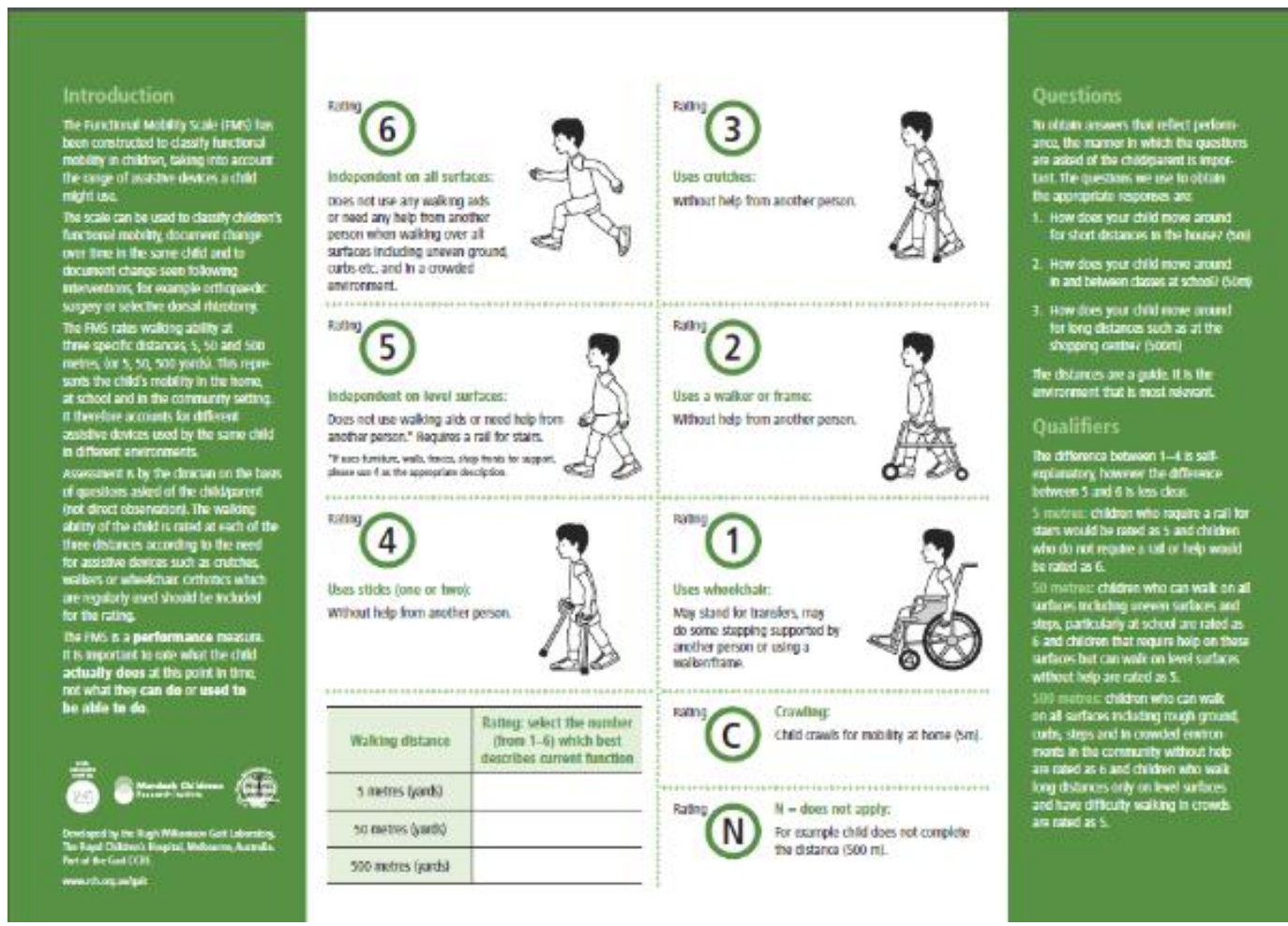

Picture 2. FMS Questionnaire 


\section{RESULTS}

From studies that have been carried out from January, 2014 to March, 2015 we collect 51 patients as a sample. 31 patients (61\%) are male and 20 patients (39\%) are female.

From the location operation, there are 41 patients with bilateral hip-knee-ankle surgery, 7 patients with knee-ankle surgery, and 3 patients with hip-knee surgery. The youngest patient was 3 years old and the oldest 15 years old with a mean age of 8.07 years. Surgery is performed before 7 years old in 23 patients and after 7 years old in 28 patients.

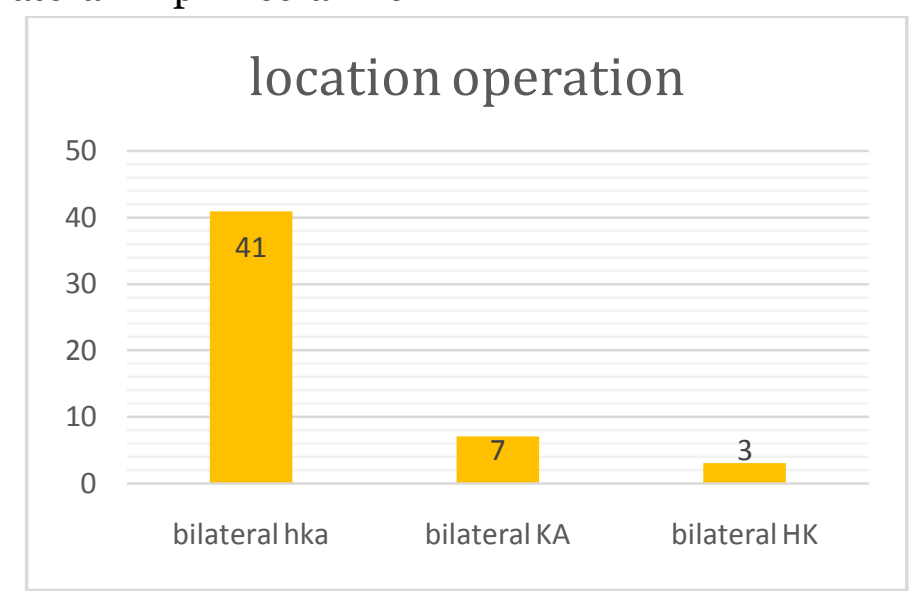

\section{Picture 3. Patient distribution of location operation}

Preoperative mobility status assessed using FMS revealed that most of the patients (38 patients) mobility status was crawled or non-walker (FMS: Crawling score) at 5, 50, and 500m. while the remaining 13 patients (25.4\%) had varying mobility at range of 5, 50, and 500m. 1 FMS score (wheelchair or standing with assistance) was obtained at $5 \mathrm{~m}$ by 5 patients, $50 \mathrm{~m}$ by 8 patients and $500 \mathrm{~m}$ by 12 patients. 2 FMS scores (using walker / frame without assistance) was obtained at
$5 \mathrm{~m}$ by 7 patients, $50 \mathrm{~m}$ by 4 patients and 500 by 2 patients. 3 FMS scores (using crutches unassisted) was obtained at 5,50 , and 50om only by 1 patient.

From evaluation of FMS scoring, we found most patient had an improvement on their mobility after SEMLS procedure (OR $>1$ ), with the time changes for 5 and 50 meters distance is at six months $(\mathrm{OR}=1.52)$ and $(\mathrm{OR}=1.47)$, and 500 meters is at 12 months $(\mathrm{OR}=3.45)$.

\begin{tabular}{|c|c|c|c|c|c|c|c|c|c|}
\hline \multirow[t]{2}{*}{ Month } & \multicolumn{3}{|c|}{5 meter } & \multicolumn{3}{|c|}{50 meter } & \multicolumn{3}{|c|}{500 meter } \\
\hline & OR & $P$ value & Ket & OR & $P$ value & Ket & OR & $P$ value & Ket \\
\hline 3 month & 0,639 & 0,048 & $<0,050$ & 0,893 & 0,998 & $>0,050$ & 0,329 & 0,998 & $>0,050$ \\
\hline ) & & & & & & & & & \\
\hline 6 month & 1,519 & 0,040 & $<0,050$ & 1,470 & 0,035 & $<0,050$ & 0,739 & 0,998 & $>0,050$ \\
\hline 9 month & 2,639 & 0,047 & $<0,050$ & 3,893 & 0,048 & $<0,050$ & 0,970 & 0,090 & $>0,050$ \\
\hline 12 month & 4,639 & 0,007 & $<0,050$ & 5,439 & 0,020 & $<0,050$ & 3,450 & 0,043 & $<0,050$ \\
\hline
\end{tabular}

Worsening in mobility if $\mathrm{OR}<1$

Improvement in mobility if $\mathrm{OR}>1$ 
We also found no significant relationships between age $(r=-0.09 ; p=0.632)$, sex $(\mathrm{r}=-0.10 ; \mathrm{p}=0.576)$ and location of contracture $(\mathrm{r}=-0.22 ; \mathrm{p}=0.222)$ with the outcome of the FMS after SEMLS.

\section{DISCUSSION}

In our study, the number of male and female patients were 31 (61\%) and 20 (39\%) respectively. This number is consistent with study conducted by A. Chounti et al., (2013) and Jarvis et al., (2004) where in their study they reported there was a male predominance in all types of $\mathrm{CP}$ cases and found more severe cases in male infants (Jarviset al., 2005; Chounti et al.,2013).

In our study, the average age of patients was 8.07 years and most of the patients fall into non walker category with crawling FMS score. This finding was consistent with the research conducted by Khan et al., (2007) in which they reported that most of $\mathrm{CP}$ cases in developing country is delayedly diagnosed with the average age of 8.5 years and cannot walk (non walker)at the time SEMLS was performed(Khan, 2007).

Decreased patient's mobility in the first 3 months post-surgery can be caused by many things. Høiness et al., (2014) suggested a few problems that arise after SEMLS procedure is postoperative pain, discomfort and psychosocial problems.

There is no significant relationship between gender and SEMLS outcome indicated by FMS score $(\mathrm{p}=0.576)$. This finding is consistent with the result from a study conducted by Chounti et al., (2013) in which involving 590 children with $\mathrm{CP}$ in Sweden and found no significant relationship between gender and patient's mobility (Chountiet al., 2013).

There is no significant relationship between number of sites in which SEMLS was performed and SEMLS outcome indicated by FMS score $(\mathrm{p}=0.222)$. This finding is consistent with the result from a study conducted bySvehlik et al., (2011) that showed no significant relationship between number of operated sites and surgery outcome.

In this study SEMLS resulted in a significant improvement of patient's mobility status indicated by FMS score despite of the average age of patients was 8.07 years and most of the patients fall into non walker category preoperatively. This finding is consistent with the result from a study conducted by Khan et al., (2007)that report SEMLS outcome in developing countries. They reported that Spastic Diplegic CP patients who have not been able to walk until the age of $7-8$ years can still benefit from SEMLS surgery, if the patient can sit independently at 4 - 5 years, and good postoperativere habilitation care (Khan, 2007).

Based on the result of this study we conclude that:

1. Most CP patients who come at Paediatric Clinic Prof. Dr. R. Soeharso, Surakarta Orthopedic Hospital is male with mean age of 8.07 years old and most of them are not yet able to walk (74.5\% with FMS score: Crawling)

2. SEMLS surgery performed in Prof. Dr. R. Soeharso Surakarta Orthopedic Hospital to Spastic Diplegic CP patients gave a good results and improve the patient's mobility status as indicated by FMS score, regardless of age at which surgery is performed and patient's mobility status before surgery.

3. FMS can be used to assess SEMLS outcomes and very responsive to changes that occur and may point the time of change

4. Age, gender, and number of sites in which SEMLS was performed have no significant effect on the SEMLS outcome as indicated by FMS score. 


\section{REFERENCE}

Abdel H. Cerebral Palsy. http://emedicine.medscape.com/article/1179555 -overview\#a4.

Adair B, Said C, Rodda J, et al., (2012). Psychometric properties of functional mobility tools in hereditary spastic paraplegia and other childhood neurological conditions. Developmental Medicine \& Child Neurology, 596 605 .

Bache E, Selber P, Graham HK (2013). The management of spastic diplegia.88104. Current Orthopaedics. Elsevier Science Ltd.

Bax M, Goldstein M, Rosenbaum P, Leviton A, Paneth N, Dan B, Jacobsson B, Damiano D (2005). Executive Committee for the Definition of Cerebral Palsy. Proposed definition and classifycation of cerebral palsy. Dev Med Child Neurol, 47: 571-576.

Bell KJ, Ounpuu S, DeLuca PA, Romness MJ (2002). Natural progression of gait in children with cerebral palsy.J PediatrOrthop, 22(5): 677-82.

Berker N, Yalcin L (2010). The Help Guide To Cerebral Palsy: Second edition. Global Help.

Bleck EE (1987). Orthopaedic Management in Cerebral Palsy 2nded, Michigan: Mac Keith.

Chounti A, Heagglund G, Wagner P, et al., (2013). Sex differences in cerebral palsy incidence and functional ability: a total population study. Acta Pædiatrica: $712-717$

Graham HK, Harvey A (2007). Assesmentof Mobility after Multi - Level Surgery for Cerebral Palsy. J Bone Joint Surg [Br], 89-B:993-4.

Harvey A, Baker R, Morris M, et al., (2009). Does parent report measure performance? A study of the construct validity of the Functional Mobility
Scale. Developmental Medicine \& Child Neurology: $181-185$.

Harvey A, Morris M (2008). Systematic review of measures of activity limitation for children with cerebral palsy. Developmental Medicine \& Child Neurology, 50: 190-198.

Harvey A, Graham HK, Morris M (2007). The Functional Mobility Scale: ability to detect change following single event multilevel surgery. Developmental Medicine and Child Neurology, 49: 603.

(2010). Reliability of the Functional Mobility Scale for Children with Cerebral Palsy.Physical \& Occupational Therapy in Pediatrics, 30(2).

Harvey A, Rosenbaum P, Hanna S, et al., (2012). Longitudinal Changes in Mobility Following Single-Event Multilevel Surgery in Ambulatory Children with Cerebral Palsy. J Rehabil Med, 44: 137-143.

Herring $J$ (2008). Disorders of the Brain In. Tachdjian's Pediatric Orthopaedics, 4th Edition, Philadelphia: Saunders Elsevier, 1277 - 1382.

Hoiness P, Capjon H, Lofterød B (2014). Pain and rehabilitation problems after single-event multi-level surgery including bony foot surgery in cerebral palsy: A series of 7 children. ActaOrthopaedica; 85(6): 646-651.

Jarvis S, Glinianaia SV, Arnaud C, et al (2005). Case gender and severity in cerebral palsy varies with intrauterine growth. Arch Dis Child, 90: 474-479.

Johnston M, Hagberg H (2007).Sex and the pathogenesis of cerebral palsy. Developmental Medicine \& Child Neurology, 49: 74-78.

Khan M (2007).Outcome of single-event multilevel surgery in untreated cerebral palsy in a developing country.J Bone Joint Surg Br, 89. 
Khwaja O, Volpe JJ (2008). Pathogenesis of cerebral white matter injury of prematurity. Arch Dis Child Fetal Neonatal Ed. 93(2):F153-61.

Marret S, Vanhulle C, Laquerriere A (2013). Pathophysiology of Cerebral Palsy.In Handbook of Clinical Neurology, Vol. 111 (3rd series) Pediatric Neurology Part I. Philadelphia: Mosby Elsevier, $169-175$.

Novacheck TF, Stout JL, Tervo R (2000). Reliability and validity of the Gillette Functional Assessment Questionnaire as an outcome measure in children with walking disabilities. $\mathrm{J}$ Pediatr Orthop, 20(1):75-81.

O'shea M (2011). Diagnosis, Treatment, and Prevention of Cerebral Palsy in NearTerm/Term Infants.ClinObstetGynecol.NIHPA.

Palisano R, Tieman B, et al (2003). Effect of environmental setting on mobility methods of children with cerebral palsy. Dev Med Child Neurol, 45(2): 113-20.

Reiss AL, Kesler SR, Vohr B, Duncan CC, et al., (2004).Sex differences in cerebral volumes of 8-year-olds born preterm. J Pediatr. 145: 242-249.

Rethlefsen S, Ryan DD, Kay R (2010). Classification System in Cerebral Palsy.OrthopClin N Am 41: 457-467.

Sawyer J (2007). Cerebral Palsy In. Campbell's Operative Orthopaedic 11th ed. Philadelphia: Mosby Elsevier, $1202-1250$.

Svehlik M, Steinwender G, et al (2011). The influence of age at single-event multilevel surgery on outcome in children with cerebral palsy who walk with flexed knee gait. Developmental Medicine \& Child Neurology: 730 735 .

Thomason P, Baker R, Dodd K (2011). Single-Event Multilevel Surgery in Children with Spastic Diplegia. J Bone Joint Surg Am. 93:451-60. 